\title{
The Application of Educational Ecology Principle in the Strategy of Enrollment and Propaganda
}

\author{
Sheng-xian GU \\ Changshu Institute of Technology \\ People's Armed Forces Department \\ Changshu, Jiangsu Province, China \\ gsx800800@163.com
}

\begin{abstract}
Admissions is an important part of college enrollment. It can meet the needs of the rapid development of colleges and universities, but also for candidates and parents to provide volunteer service. Combined with the principles of educational ecology, colleges and universities can improve the publicity strategy, the use of relevant principles; enrich the way of publicity and publicity methods, targeted to carry out publicity work to improve the effectiveness of enrollment publicity to attract high quality students to meet the needs of rapid development of colleges and universities.
\end{abstract}

Keywords—educational ecology; enrollment propaganda; strategy;

\section{I.INTRODUCTION}

With the rapid development of higher education in China, the scale of enrollment gradually expanded, higher vocational education and remote network education is also rapidly rising, leading to shortage of students and graduates employment Market expansion. Followed by the work of the College Admissions Office should also change with the times, can not simply in the admissions stage according to enrollment plan admission students, but should change the work of thinking, the development of enrollment programs, targeted to carry out long-term Of the recruitment and consultation activities, and strive to improve the quality of school students, for the school reform and development to provide students with protection.

Educational ecology theory is the rise of a theory in recent years, mainly to explore the principles of education and ecology of the relationship between the integration and use. The ecologicalization of education is the necessity of the development of higher education in our country. By using the principle of educational ecology, we can adopt feasible educational management measures, rationalize the educational resource allocation with people-oriented educational philosophy, efficient and sustainable development of the ecological system, and promote the work of the integration of university and coordinated development.

This paper aims to provide a useful theoretical reference for the enrollment and propaganda work of colleges and universities through the educational ecology theory, from the top-level program design, the propaganda strategy formulation, the establishment of the "big data" information base of the enrollment propaganda, to promote and promote the specific practice of enrollment.

\section{II.ANALYSIS OF THE ECOSYSTEM THEORY OF ENOROLLMENT IN COLLEGES AND UNIVERSITIES}

The key to the practice of educating the ecology of education is to clarify the basic principles, the use methods and the basic characteristics of educational ecology. In the value orientation, the educational ecology is based on the theory and method of applying ecology to study educational phenomena and educational problems and explore the law of education. In the method of generating, the educational ecology focuses on putting the various educational institutions and structures in contact with each other, and to maintain them and are influenced by the wider societies.

There is a high degree of consistency and coherence between the two aspects of educational ecology and the internal 
relevance of the propaganda work of college enrollment. Education ecology concept, for us from the macro integration of existing enrollment promotional resources, from the system to optimize the recruitment of propaganda work structure, from the linkage mechanism to stimulate the enthusiasm of the propaganda work, provides a new way of thinking and methods.

Comprehensive view of the above, college enrollment propaganda work should be a system by the internal and external environment together constitutes a complex multi-ecological system. According to the requirements of educational ecology, it is necessary to strengthen the research on the ecosystem structure of college enrollment propaganda work. First, we should strengthen the research from three aspects; the second is to explore from the concept of university-centered schools within the relationship between the various ecological factors and the overall effect of propaganda work, resource integration issues; Third, from the microscopic study of the candidates as the center of the relevant factors, we will closely strengthen the communication and contact between the enrollment propagandists and the candidates, integrate the universities, high school, society, family and other factors, and work together to promote the propaganda work of colleges and universities, and volunteer to fill the candidates. I mainly from the perspective of colleges and universities to analyze and explore the work of college enrollment propaganda work ecosystem.

\section{III.THE COLLEGE ENROLLMENT PROPAGANDA WORK IN THE ECOLOGICAL PROBLEMS}

At present, with the increasing pressure of students, the colleges and universities have been paying more and more attention to the publicity and publicity work, and some colleges and universities have achieved certain results. However, from the perspective of educational ecology, there are still some outstanding problems such as "one-way propaganda", "teacher-student opposition", "caliber" and "expectation of disagreement", which are urgently needed to be studied and solve. This is because the college enrollment propaganda work is not self-contained, there is no necessary theoretical support, most colleges and universities only in the voluntary filling stage was temporarily deployed counselors (or part of the full-time teachers) set up enrollment propaganda team, divided into a number of groups to consult Point publicity, publicity can not guarantee, perfunctory, walk and other issues gradually appear, we need to be studied and resolved.

\section{A. Ecological structure is less reasonable}

Reasonable ecological structure is the basis for the ecosystem to maintain a smooth operation. Although the existing leadership institutions, team structure and management institutions of the university enrollment propaganda work have been basically established, the leadership and teachers and students of most colleges and universities still pay attention to the degree of attention to the enrollment propaganda and do not face the current situation and pressure of competition. In the leadership structure, often not enough attention, college leaders are mostly famous phenomenon, not really concerned with and participate in the recruitment of propaganda work; in the team structure, there is no strong fighting team, one to recruit staff to change frequently, In the management, the Admissions Office, the Student Affairs Office, the Academic Affairs Office, the Logistics Department, the Communist Youth League Committee, the Scientific Research Department and other relevant administrative departments of the line is not formed in a reasonable manner. The management of the trail is not out of the way. , Basically no structure at all.

\section{B. Poor operating mechanism}

The level and stability of the internal mechanism of the ecosystem is the embodiment of the quality of the ecosystem. The mechanism of the propaganda work ecosystem in colleges and universities is more or less the existence of this imperfect problem, including the selection and selection mechanism of propagandists, the recruitment and rewards and punishments mechanism, the propaganda process guarantee and supervision mechanism, and the propaganda result evaluation mechanism. Some of these content is not perfect, and some unscientific, and some have been missing, and some have been backward, etc., to a certain extent, affected the good work of the recruitment of publicity work, but also affect the actual effect of the actual enrollment propaganda. 


\section{Ecological process is less smooth}

The ecological process of the ecosystem is the process of the system operation. The ecological process of college enrollment and propaganda ecosystem is the embodiment of the achievements of running schools in colleges and universities, and it is also a manifestation of the quality of personnel training in colleges and universities. Finally, the relevant factors are realized through the propaganda and propaganda work.

The process of propaganda work is the process of the interaction between the relevant components and related factors. In the process of enrollment propaganda work, there are some block, delay, blunt, mechanical and other non-smooth phenomenon, such as the slogan simply stand in the perspective of their own colleges and universities, publicity practice does not consider the characteristics of high school students and candidates personal expertise, promotional materials Simply copy the contents of previous years, enrollment propaganda organization in the process of reluctance to cooperate with the relevant departments, these are not very smooth impact on the actual effect of college enrollment propaganda work.

\section{THE EDUCATIONAL ECOLOGY FROM THE PERSPECTIVE OF PROMOTING THE PROMOTION OF COLLEGE ENROLLMENT AND EFFECTIVE MEASURES}

\section{A. To strengthen the "education" and "service" concept,optimize the recruitment and publicity management system}

Education ecology from the perspective of college enrollment propaganda work should break through the limitations of management and closed, pay attention to the coordination and equality of components within the system, emphasizing the full play of the role of the parties to achieve the effectiveness of enrollment and penetration Sex, and ultimately for the university to attract more quality students, to serve the sustainable development of colleges and universities. Therefore, to improve the effectiveness of college enrollment propaganda work, we should first optimize the management system of college enrollment, with scientific management mechanism to encourage candidates, high school, relevant departments within the university, enrollment propaganda and other different components of the subjective initiative, integration of the elements, promote the interaction of each component, build a network, three-dimensional communication and coordination mechanism, in the process of interaction to improve the efficiency of enrollment propaganda work.

\section{$B$. The rational use of the principle of educational niche, targeted to do the publicity work}

In the traditional teaching evaluation mode, the only standard of evaluation for students is still the grade. In the enrollment of propaganda ecosystem, the evaluation of candidates is based on college entrance examination scores. A single evaluation system has caused a serious niche overlap phenomenon, which not only to the college enrollment propaganda work has brought some trouble, but also brought a certain job convenience. Colleges and universities can be distributed through the scores of candidates, analysis of the niche of different candidates, according to the candidates score, targeted to carry out propaganda work, such as through advanced educational philosophy, new scholarships, further studies to attract high scores, through professional selection of a wide range of employment prospects to attract points in the candidates, through the transfer of professional system, innovation and practice to attract low scores of candidates. Through the different scores of candidates to take different publicity strategies, better highlight the characteristics and advantages of college education, to attract high scores candidates to improve the quality of students.

\section{The rational use of the law of tolerance and the most appropriate principle, appropriate publicity work}

In general, most colleges and universities to carry out recruitment and propaganda work are basically concentrated in the college entrance examination volunteer report period, time is short, large amount of information. For colleges and universities, the need to arrange more human, material and financial resources to do the publicity work. However, for the candidates, they need in a few days to determine their own personality and preferences, according to their own interests to determine their own future career planning, the initial selection of the proposed professional direction. To determine the general direction of the professional, 
the candidates need to run the university level, school status, school characteristics and other information to study and judge, selected for their own fill in the school and professional. From the point of view of the candidates, they need in a very short period of time to find and receive a lot of information on the university and professional, it is easy to produce mental fatigue or even resistance. Therefore, colleges and universities to carry out recruitment propaganda need to combine the law of tolerance, in the psychological acceptance of candidates within the publicity work to avoid a simple and crude way to achieve the best results.

\section{CONCLUSION}

In short, colleges and universities are facing increasing fierce competition from the source of competition. Recruitment is not only a simple completion of the enrollment plan, but through the recruitment of publicity, enrollment analysis and other means to improve the quality of students. The strategy of enrollment propaganda is a very important factor that affects the effect of enrollment. With the principle of educational ecology, it can provide some theoretical support for the formulation of enrollment propaganda strategy, and also guide the implementation of this propaganda to a certain extent. Fundamentally, colleges and universities only have a solid grasp of the quality of personnel training, and effectively improve the school strength, highlighting the characteristics of running a school in order to win a good reputation of the majority of candidates. Admissions propaganda, to choose a reasonable way and way to avoid weaknesses, flexible use, to improve the effectiveness of enrollment publicity, and strive to use the least investment to achieve the best publicity, to the quality of students to promote the sustained, healthy and stable development of the college.

\section{REFERENCES}

Educational ecology theory is the rise of a theory in recent years, mainly to explore the principles of education and ecology of the relationship between the integration and use[1]. The ecologicalization of education is the necessity of the development of higher education in our country. By using the principle of educational ecology, we can adopt feasible educational management measures, rationalize the educational resource allocation with people-oriented educational philosophy, and construct a work under the premise of respecting the individual differences between teachers and students Healthy, efficient and sustainable development of the ecological system, and promote the work of the integration of university and coordinated development[2].

Comprehensive view of the above, college enrollment propaganda work should be a system by the internal and external environment together constitutes a complex multi-ecological system[3][4]. This system can be divided into three aspects: the macro social environment, the middle school environment and the micro-subject environment from the structural level, and each level contains the consciousness, the system and the material content, and is the whole of the ecological factor synthesis Schema[5].

In the enrollment of propaganda ecosystem, the evaluation of candidates is based on college entrance examination scores[6]. A single evaluation system has caused a serious niche overlap phenomenon, which not only to the college enrollment propaganda work has brought some trouble, but also brought a certain job convenience[7].

[1] Wu Ding Fu, Zhu Wee-wee. Educational ecology [M]. Nanjing: Jiangsu Education Press, 1990.

[2] Fan Guorui. Educational ecology [M]. Beijing: People's Education Press, 2000.

[3] Deng Xiaoquan. Educational ecology research for twenty years [J]. Educational Theory and Practice, 2009, 29 (5).

[4] Wu Dingfu. Educational ecology [J]. Journal of Nanjing Normal University (Social Science Edition), 1988 (3).

[5] Zhang Jianfa. College student's enrollment of psychological strategies and communication skills [J] .Heilongjiang Higher Education Research, 2004, (6).

[6] Yu Juan, etc. Higher music institutions enrollment management reform [J]. China Adult Education, 2013, (15).

[7] Wang Ronghui. Promotion theory in college enrollment propaganda in the application [J]. Heilongjiang Higher Education Research, 2006 (9). 